\title{
Value added usage of granular steel slag and milled glass in concrete production
}

\author{
Sajjad Ali*, Shahid Iqbal**, Shah Room***, Ahsan Ali**** and Zia ur Rahman* \\ *Department of Civil Engineering, CECOS University of IT and Emerging Sciences, Peshawar, Pakistan \\ **Department of Civil Engineering, Sarhad University of Science and Information Technology, Peshawar, Pakistan \\ ***Department of Civil Engineering Technology, University of Technology, Nowshera, Pakistan \\ ****Department of Civil Engineering, Qaid e Awam University College of Engineering, Science and Technology, Larkana, Pakistan \\ Corresponding Author: Shahrome313@yahoo.com
}

Submitted: 09/05/2019

Revised: $\quad 06 / 11 / 2020$

Accepted: $12 / 11 / 2020$

\begin{abstract}
Industrial development has generated enormous conveniences for humans at the cost of environmental pollution. Cement production is a major cause of carbon dioxide emission in the construction industry, and utilization of a large number of aggregates in concrete is causing scarcity of natural resources and irreversible depletion. The practice of utilizing industrial wastes in the production of concrete can be a useful solution. In this research, green concrete of enhanced properties is produced by incorporation of milled glass as partial replacement of cement, and fine aggregates are replaced by granular steel slag with different dosages. Ten types of concrete mixes substituting 10\%, 20\%, and $30 \%$ of cement by glass powder (GP) and $40 \%, 60 \%$, and $80 \%$ of sand by granular steel slag (SS) were assessed in terms of rheological, mechanical, and microstructural properties. Results indicated that concrete having $80 \%$ granular steel slag and $20 \%$ glass powder shows a maximum increase of $42 \%, 16 \%, 16 \%$, and $14 \%$ in splitting tensile strength, flexural strength, modulus of elasticity, and compressive strength, respectively. Scanning electron microscopy depicts the formation of secondary calcium silicate hydrate (CSH) and improved packing density in concrete mixes having granular steel slag and glass powder. Thus, granular steel slag and glass powder can effectively be used as cement and sand replacement in the production of value-added green economical concrete, reducing environmental pollution.
\end{abstract}

Keywords: fresh concrete properties; glass powder; mechanical concrete properties; steel slag; green concrete.

\section{INTRODUCTION}

Concrete is the man-made world's most commonly utilized construction material with an evaluated production of 10 billion tons every year (Abukersh and Fairfield, 2011). It is a mixture of cement, aggregates, and water with definite proportions. Chemical admixtures are also used in the concrete to obtain varied properties. Cement is the essential component of concrete, but it requires high amount of energy for production and emits $7 \%$ of total $\mathrm{CO} 2$ to the atmosphere (Imbabi et al., 2012; Carrigan and Mckenna, 2012). The consumption of natural materials in concrete causes the shortage of natural resources and demolition of the environment, even ecology. To overcome these problems, the practice of utilizing waste materials can play a vital part in reducing the ingestion of cement and natural aggregates in concrete, thus lowering environmental pollution.

Researchers have taken keen interest to utilize waste materials in concrete. Different industrial wastes like fly ash, silica fume, marble dust, steel slag, and glass powder are utilized in concrete, and encouraging results are obtained. Concrete containing fly ash in different proportions increases its compressive strength by $13.5 \%$, split tensile strength 
by $26 \%$, and flexural strength of concrete by $10 \%$ (Iqbal et al., 2017). Similarly, the use of silica fume in concrete not only improves the workability, but also increases its compressive strength by $18.8 \%$ (Srivastava et al., 2015).

The glass powder abundantly produced industrial waste with almost 130 million tons per year production worldwide (Rashad, 2014). Post-used blended glass is an additional cementitious waste product, which can decrease the global environmental impact of concrete production and usage (Deschamps et al., 2018). Glass is also enriched with silica, and it is amorphous in nature. It shows pozzolanic properties having particle size less than $75 \mu \mathrm{m}$ (Silva et al., 2014). Therefore, glass powder can be consumed in the concrete to substitute some portion of cement as a filler or binder material. Different investigations have been conducted to study the behavior of concrete with the substitution of glass powder. An increase in glass powder content increases the workability of concrete, and this is due to the nonabsorbent nature of glass (Schwarz et al., 2007). Literature shows that, to attain better compressive strength in concrete, 10\% of cement can be safely substituted with glass powder confirming all other prerequisites of normal concrete maturity. The compressive strength of glass powder substituted concrete increases as the age of concrete increases depicting later pozzolanic reactivity (Yu et al., 2016; Parghi and Alam, 2016). It is reported that a 24\% increase occurred in the compressive strength when cement was replaced with $20 \%$ glass powder (Raju and Kumar 2014). Similarly, 18\% improvement occurred in the splitting tensile strength with the addition of glass powder possibly due to enhancement in the interfacial transition zone properties (Aliabdo et al., 2016).

Steel slag is another useful industrial waste, produced as a by-product in the steel manufacturing process. The steel production yields steel slag (15-20\%), and most of it is disposed as a waste material (Hou et al., 2012; Motz and Geiseler, 2001). This disposition causes pollution and inadequacy of space for landfilling. Researchers have taken interest in replacing the aggregates with steel slag, and good improvements are reported in the concrete properties (Qasrawi et al., 2009; Zelic, 2005). Cement partially replaced by steel slag can reduce 47.5\% greenhouse gas emissions if compared with the cement based concrete subject to the condition of non-constrained supply; this percentage reduces to $1 \%$ with constraint supply of slag (Crossin, 2015). The addition of steel slag in concrete caused the drop in workability due to its rough surfaces (Roslan et al., 2016; Netinger et al., 2013). The fresh concrete density increased with the application of steel slag probably due to the higher density of steel slag (Khan et al., 2016). There was almost a $20 \%$ increase in the concrete compressive strength by the addition of steel slag in the concrete (Huang et al., 2016). The modulus of elasticity increased by $10 \%$ when steel slag was substituted in the concrete (GonzálezOrtega et al., 2014).

\section{STUDY TARGETS, SCOPE, AND ORIGINALITY}

Although some research work is reported using milled glass in combination with steel slag in self-compacting concrete (Rehman et al., 2018), their combined performance is not studied yet in normal weight concrete. Most research involves the individual performance of milled glass and steel slag in normal weight concrete. The individual utilization of milled glass has undesirable performance in concrete beyond $20 \%$ cement replacement. Similarly, the individual use of steel slag reduces workability.

The steel slag added concrete has better compressive strength as well as tensile strength, but its high content in concrete has limited utilization due to a reduction in workability (Netinger et al., 2013). To avoid this limitation, milled glass can be effectively utilized with steel slag to give concrete good workability. This research aims at developing concrete having good mechanical properties and workability.

The fresh concrete properties considered in this study are density, air content, and workability, while hardened concrete properties studied are flexural strength, split tensile strength, modulus of elasticity, and compressive strength.

The main objectives of this research work are as follows:

- Studying the mutual effect of steel slag and milled glass on density, air content, and workability of concrete.

- Investigating the mutual behavior of steel slag and milled glass on the modulus of elasticity, compressive, split 
tensile, and flexural strength of concrete.

○ Studying the microstructure of concrete containing steel slag and milled glass.

In this study, a reference mix was taken by trial, while steel slag and milled glass were added to other mixtures in different proportions, and the results were compared.

\section{MATERIALS AND METHODS \\ Materials}

\section{Aggregates and slag}

In this study, crushed coarse aggregates, $4-18 \mathrm{~mm}$ in size, were used in all the mixes. Natural sand and steel slag, 0-4 mm, was used as fine aggregate. The aggregates properties are given in Table 1 .

Table 1. Aggregates properties.

\begin{tabular}{|c|c|c|c|}
\hline Material & Water absorption (\%) & Specific gravity & Size (mm) \\
\hline Coarse aggregate & 0.80 & 2.65 & $4-18$ \\
\hline Sand & 0.81 & 2.87 & $0-4$ \\
\hline Slag & 1.21 & 3.10 & $0-4$ \\
\hline
\end{tabular}

\section{Milled glass and cement}

The particle size of milled glass was converted to less than $75 \mu \mathrm{m}$ in the PCSIR laboratory Peshawar, Pakistan, while ordinary Portland cement was used in the research work. The properties of milled glass and cement are presented in Table 2.

Table 2. Properties of milled glass and cement.

\begin{tabular}{|c|c|c|c|c|c|c|c|c|c|c|}
\hline \multicolumn{7}{|c|}{ Chemical properties } & \multicolumn{2}{c|}{ Physical properties } \\
\hline Constituent & $\mathrm{Na}_{2} \mathrm{O}$ & $\mathrm{K}_{2} \mathrm{O}$ & $\mathrm{SO}_{3}$ & $\mathrm{CaO}$ & $\mathrm{Fe}_{2} \mathrm{O}_{3}$ & $\mathrm{Al}_{2} \mathrm{O}_{3}$ & $\mathrm{SiO}_{2}$ & $\mathrm{MgO}$ & $\begin{array}{c}\text { Specific } \\
\text { gravity }\end{array}$ & $\begin{array}{c}\text { Surface } \\
\text { area }\end{array}$ \\
\hline Unit & \multicolumn{7}{|c|}{$\%$} & $\mathrm{~g} / \mathrm{cm}^{3}$ & $\mathrm{~cm}^{2} / \mathrm{g}$ \\
\hline OPC & 0.9 & 0.4 & 2.9 & 65.7 & 3.7 & 3.4 & 21.9 & 1.5 & 3.15 & 2184 \\
\hline GP & 11.6 & 0.03 & 0.1 & 8.79 & 0.08 & 0.15 & 74.3 & 3.91 & 2.71 & 2120 \\
\hline
\end{tabular}

\section{Methodology}

This study was directed to analyze the fresh and hardened properties of concrete containing steel slag and milled glass. Ten different combinations were studied in this investigation with 0.5 water-cement ratio. A reference mix without any replacement was prepared. Combination of milled glass and steel slag was substituted to a set of nine mixes with $10 \%, 20 \%$, and30 \% substitution of cement by milled glass and $40 \%, 60 \%$, and $80 \%$ of sand replaced 
by steel slag. The fresh concrete properties under consideration were density, air content, and workability, while mechanical properties comprise modulus of elasticity (MOE), compressive strength (CS), split tensile strength (STS), and flexural strength (FS). All the tests were executed according to ASTM specifications. To investigate the fresh concrete properties, workability was determined using slump cone test as per ASTM C143/C143M (ASTM C 143/C $143 \mathrm{M}$ ), while density and air content were determined using ASTM C138/C138M (ASTM C 138). For mechanical properties of concrete, cylindrical specimens with $200 \mathrm{~mm}$ height and $100 \mathrm{~mm}$ diameter were casted. Demolding was performed after 24 hours of casting for all the concrete samples, and they were placed in water for saturated curing according to ASTM C192/C192 M (ASTM C 192/C 192M-02). Three samples were tested at 28 days of age of concrete for compressive strength as per ASTM C39/C39M (ASTM C 39), splitting tensile strength as per ASTM C496/C496M (ASTM C 496-04), and modulus of elasticity as per C469/C469M (ASTM C 469-94). To investigate the flexural strength, prism samples having dimensions of $100 \mathrm{~mm} \times 100 \mathrm{~mm} \times 350 \mathrm{~mm}$ were prepared and tested at 28 days of concrete age according to ASTM C78/C78M (ASTM C 78-02). The flexural strength test arrangement is shown in Figure 1. To study the microstructure, scanning electron microscopic (SEM) analysis was performed for every concrete mix.
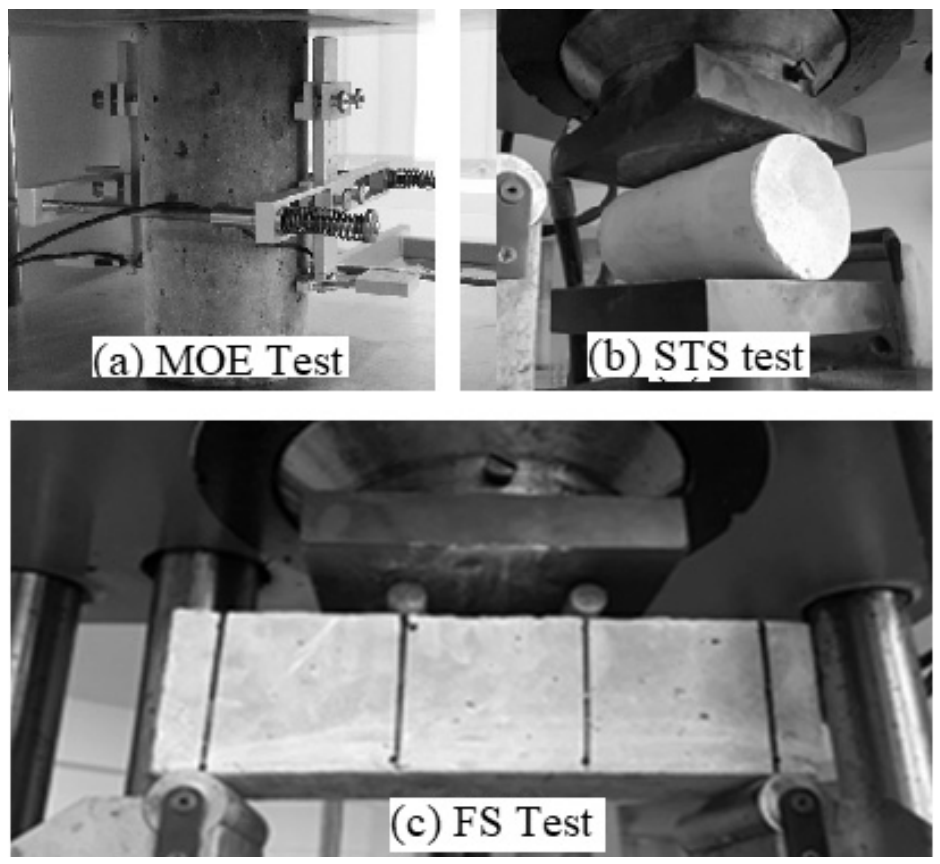

Figure 1. Test arrangement. (a) MOE test. (b) STS test. (c) FS Test.

\section{Concrete mix design}

To study the effect of milled glass and steel slag on fresh and hard state concrete properties, ten types of concrete mixtures were arranged. A normal concrete mixture was selected on trial basis to achieve the desired properties at constant water to powder ratio (w/p) of 0.5 , and then $10 \%, 20 \%$, and $30 \%$ cement was substituted with milled glass, while granular steel slag was used as $40 \%, 60 \%$, and $80 \%$ fine aggregate replacement for subsequent nine mixes. The quantities of all the other entities of concrete remained constant. Material quantities of various concrete mixes are presented in Table 3. 
Table 3. Concrete mix proportions.

\begin{tabular}{|c|c|c|c|c|c|c|c|}
\hline \multirow{2}{*}{ Mix } & \multicolumn{7}{|c|}{ Quantities (kg/m $\mathbf{3}$} \\
\cline { 2 - 8 } & w/p & cement & Milled glass & Water & sand & Steel slag & Coarse aggregate \\
\hline $\mathrm{C}_{0}$ & 0.5 & 405.0 & - & 231.87 & 822.64 & - & 1013.08 \\
\hline $\mathrm{C}_{1}$ & 0.5 & 364.5 & 40.5 & 231.87 & 493.59 & 355.05 & 1013.08 \\
\hline $\mathrm{C}_{2}$ & 0.5 & 364.5 & 40.5 & 231.87 & 533.43 & 329.59 & 1013.08 \\
\hline $\mathrm{C}_{3}$ & 0.5 & 364.5 & 40.5 & 231.87 & 164.52 & 710.85 & 1013.08 \\
\hline $\mathrm{C}_{4}$ & 0.5 & 324.0 & 81.0 & 231.87 & 493.59 & 355.05 & 1013.08 \\
\hline $\mathrm{C}_{5}$ & 0.5 & 324.0 & 81.0 & 231.87 & 533.43 & 329.59 & 1013.08 \\
\hline $\mathrm{C}_{6}$ & 0.5 & 324.0 & 81.0 & 231.87 & 164.52 & 710.85 & 1013.08 \\
\hline $\mathrm{C}_{7}$ & 0.5 & 283.5 & 121.5 & 231.87 & 493.59 & 355.05 & 1013.08 \\
\hline $\mathrm{C}_{8}$ & 0.5 & 283.5 & 121.5 & 231.87 & 533.43 & 329.59 & 1013.08 \\
\hline $\mathrm{C}_{9}$ & 0.5 & 283.5 & 121.5 & 231.87 & 164.52 & 710.85 & 1013.08 \\
\hline
\end{tabular}

\section{RESULTS AND DISCUSSION}

\section{Fresh properties of concrete}

In the fresh state, air content, density, and workability were studied in this research work. The outcome of milled glass on workability at constant levels of steel slag is graphically presented in Figure 2 . The result shows that the increasing amount of milled glass enhances the workability of concrete at constant steel slag content. Previous research on the utilization of milled glass has also indicated improvement in workability with increasing content milled glass (Ali et al., 2017; Castro and Brito, 2013). This improvement may be attributed to the nonabsorbent nature as well as smooth surfaces of milled glass particles (Ali and Al-Tersawy, 2012).

Similarly, the influence of steel slag on concrete workability at constant levels of milled glass is shown in Figure 3 , which shows that reduction occurred in the workability with the increased dosage of steel slag level in the mixture. Reduction in workability with the increasing amount of steel slag is also reported by some other researchers (Mengxiao et al., 2015; San-Jose et al., 2014). Steel slag particles have rough surfaces, which may have some contribution in decreasing the workability of concrete (Biskri et al., 2017).

The air content is influenced by the presence of steel slag in the concrete mix. The increase occurred when steel slag content was increased in the mixture at constant milled glass level. The increasing quantity of milled glass reduces the air content when the amount of steel slag is kept constant in the concrete mixture. The addition of steel slag also increased the fresh concrete density. There was no marked effect on fresh concrete density with the addition of milled glass. 


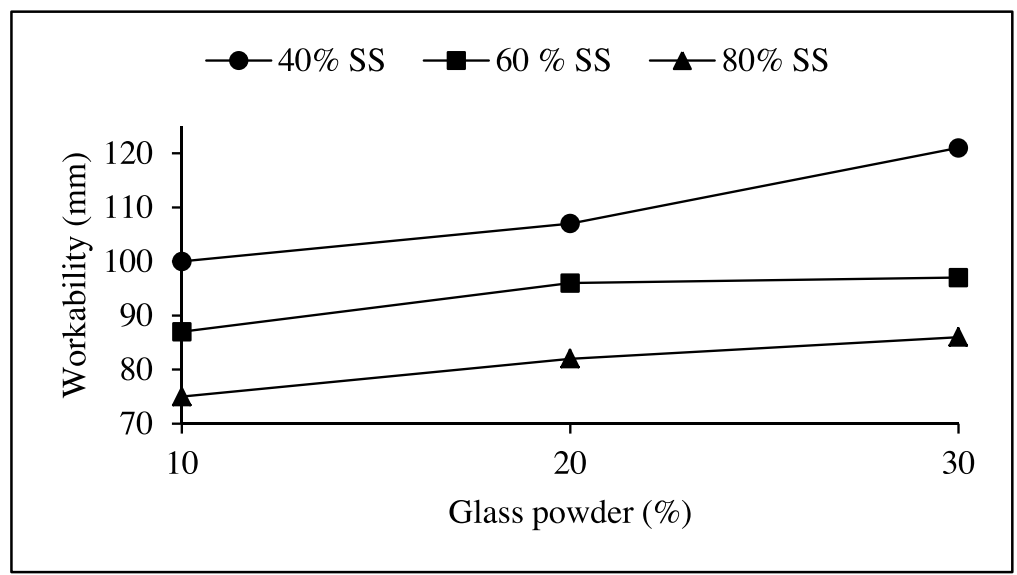

Figure 2. Effect of milled glass on workability of steel slag incorporated concrete.

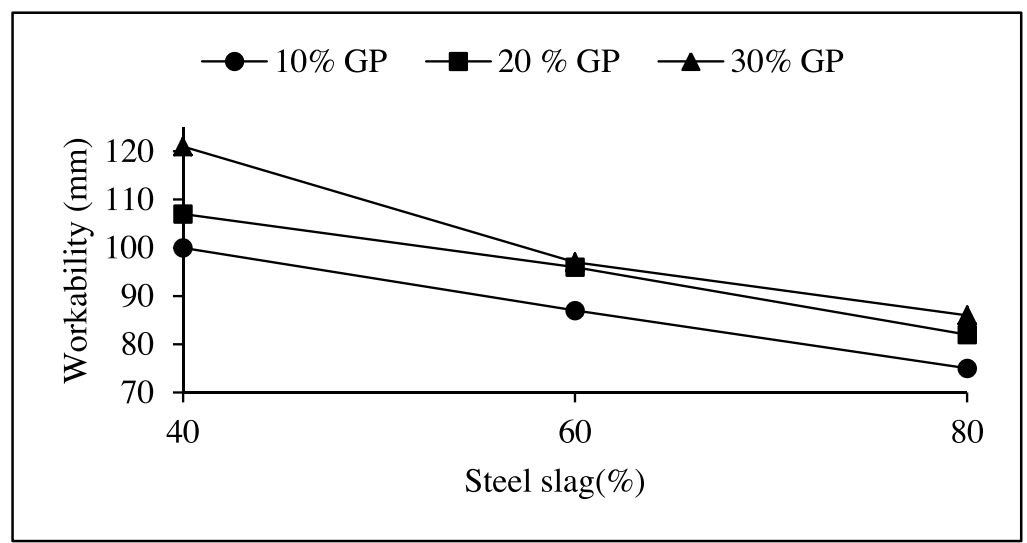

Figure 3. Effect of steel slag on workability of milled glass incorporated concrete.

\section{Hardened properties of concrete}

The test arrangement for modulus of elasticity test, splitting tensile strength test, and flexural strength test is shown in Fig. 1, and results are discussed in detail in the following sections.

\section{Compressive strength}

The effect of milled glass on compressive strength (28 days) of concrete is represented in Figure 4 . At $10 \%$ milled glass in the mix, the rise in compressive strength was $1.72 \%, 3.70 \%$, and $4.60 \%$ at the constant level of steel slag, i.e., $40 \%, 60 \%$, and $80 \%$, respectively, which is in conformity with the results of Rodier and Savastano (2018). When the content of milled glass was increased to $20 \%$, more development occurred in the compressive strength of concrete as reported by (Tho-In, et al. 2018), and the compressive strength increased by $4.00 \%, 8.85 \%$, and $14.00 \%$ at $40 \%$, $60 \%$, and $80 \%$, respectively. This was the maximum replacement for which the highest increase occurred in the compressive strength of concrete. Further, increasing the amount of milled glass in the mixture, no further increase was reported in the compressive strength. These results were still higher than reference concrete. At $30 \%$ milled glass content, the compressive strength was $4.28 \%, 7.42 \%$, and $9.00 \%$ higher than reference concrete at $40 \%, 60 \%$, and $80 \%$ steel slag content. Other researchers have also suggested $20 \%$ milled glass content as the optimum value for higher compressive strength in the concrete mixture (Lu et al., 2017; Afshinnia and Rangaraju, 2016). The influence of steel slag on compressive strength is displayed in Figure 5. Figure 5 shows an increase in the compressive strength with the increasing amount of steel slag in the concrete mixture. The highest development in the compressive strength 
was reported at $80 \%$ steel slag, which was added in combination with $20 \%$ milled glass. The compressive strength obtained for this combination was $14 \%$ more than the normal concrete. Therefore, the $80 \%$ steel slag and $20 \%$ milled glass may be considered as the optimum dosage in the concrete mixture.

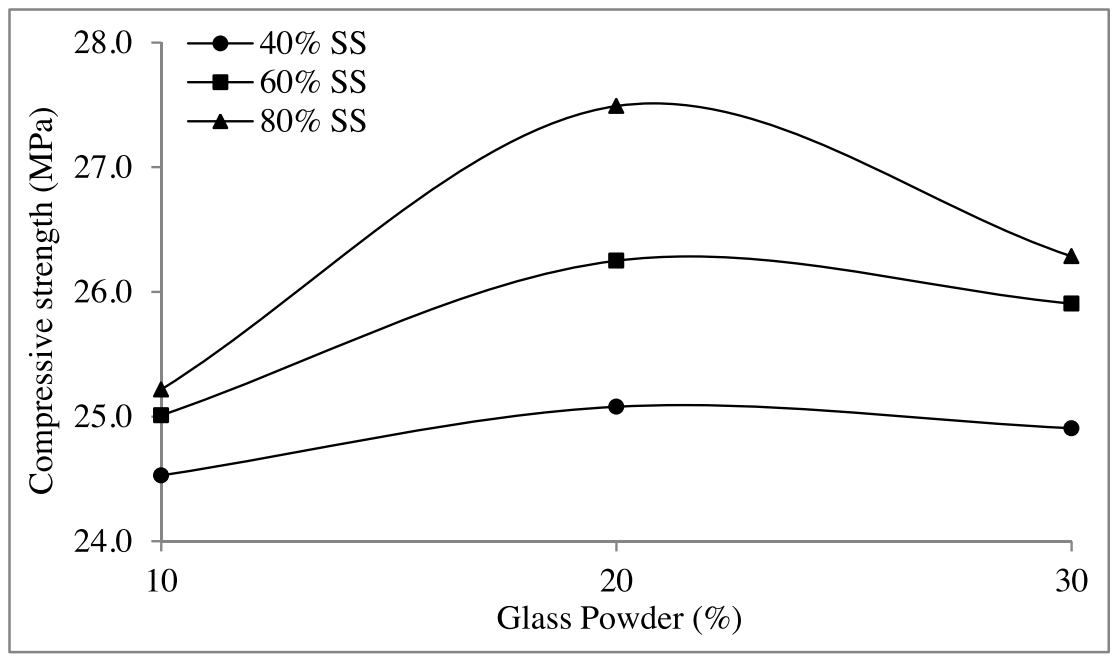

Figure 4. Effect of milled glass on compressive strength of steel slag incorporated concrete.

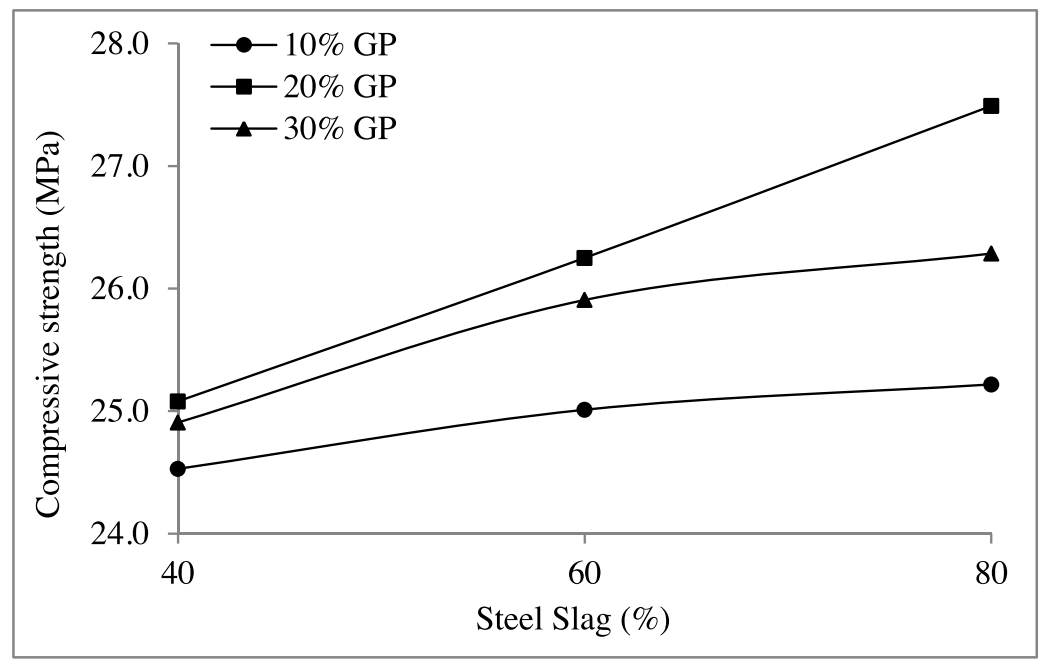

Figure 5. Effect of steel slag on compressive strength of milled glass incorporated concrete.

\section{Splitting tensile strength}

Influence of milled glass on splitting tensile strength of concrete is graphically represented in Figure 6 . The results show development splitting tensile strength at $10 \%$ and $20 \%$ milled glass level in the mix. At $30 \%$ milled glass content, no more improvement was observed in the splitting tensile strength of concrete. The influence of steel slag on splitting tensile strength of concrete at constant milled glass content is represented in Figure 7 . The splitting tensile strength increased as the steel slag quantity was increased in the concrete mix. The highest improvement in the splitting tensile strength was reported for $80 \%$ steel slag and $20 \%$ milled glass level in the mix, which was $42 \%$ more than the normal concrete. 


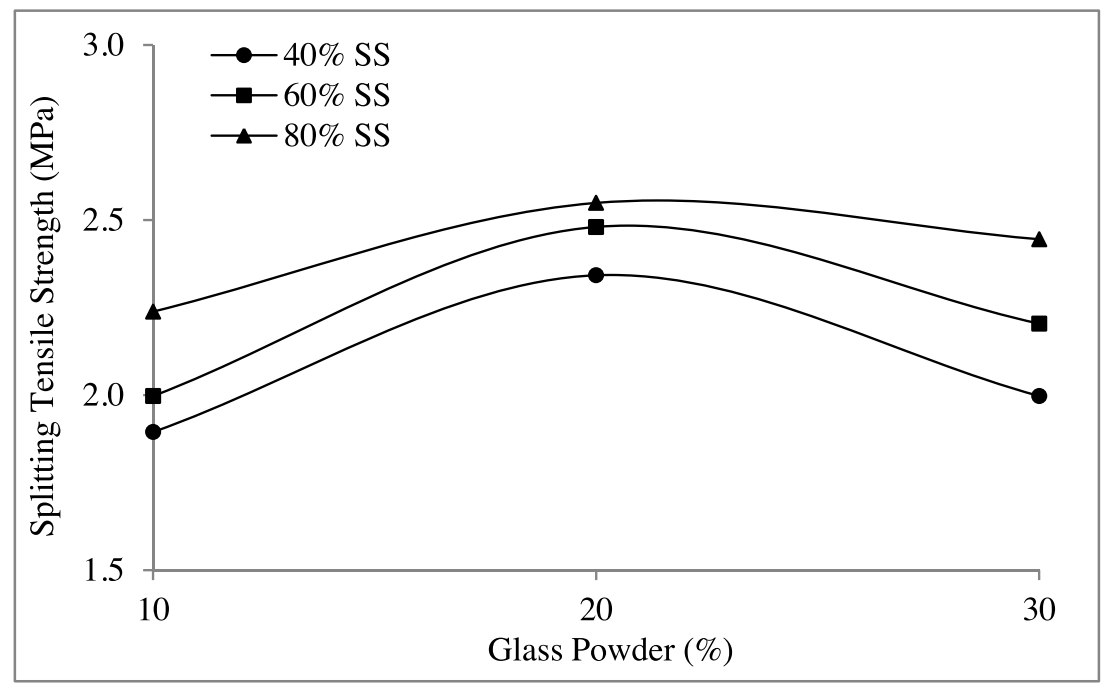

Figure 6. Effect of milled glass on split tensile strength of steel slag incorporated concrete.

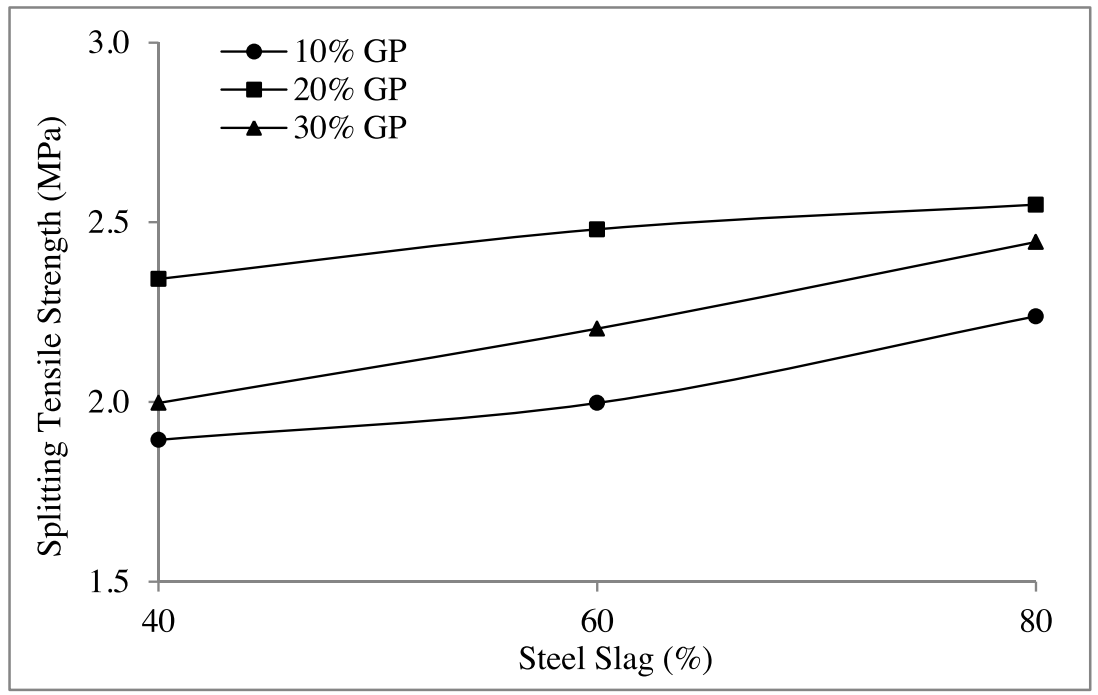

Figure 7. Effect of steel slag on split tensile strength of milled glass incorporated concrete.

\section{Flexural strength}

Flexural strength test results of milled glass incorporated concrete are displayed in Figure 8. Improvement occurred in the flexural strength for $10 \%$ and $20 \%$ substitution of milled glass in the mixture as reported by Tho-In et al. (2018) but decreased as $30 \%$ milled glass was substituted in the concrete mix. The effect of steel slag on flexural strength is represented in Figure 9. The increasing quantity of steel slag in the concrete mixture also increased the flexural strength. The highest increase in the flexural strength is reported for $80 \%$ steel slag and $20 \%$ milled glass incorporation in the mixture. This increase was $16 \%$ more than the normal concrete. 


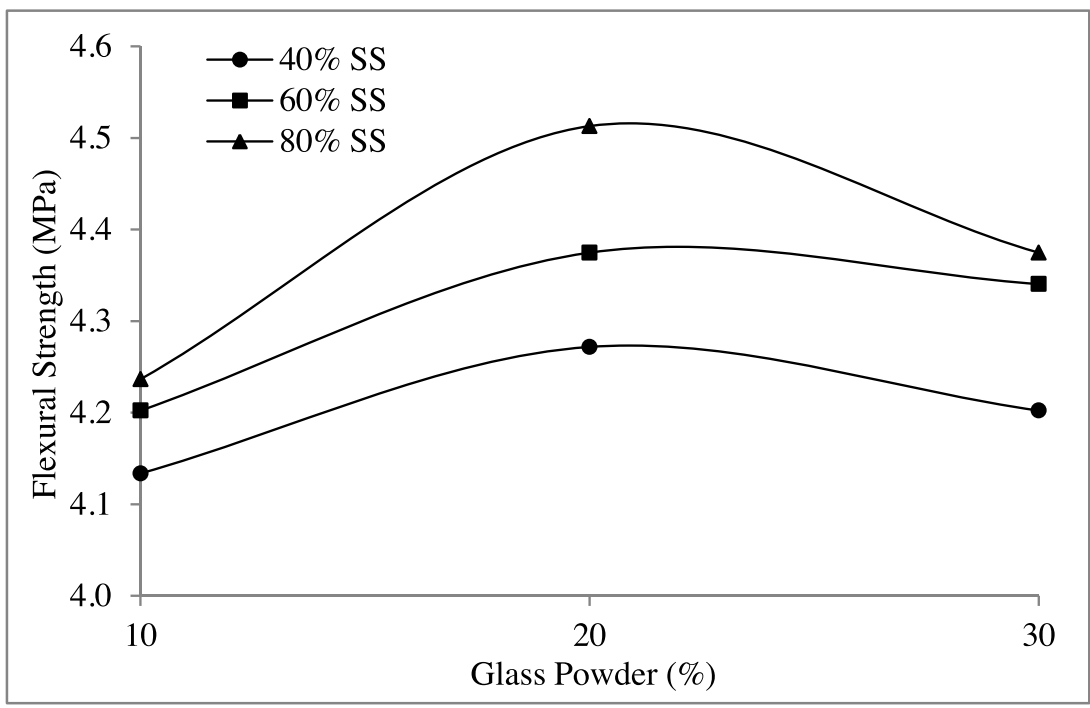

Figure 8. Effect of milled glass on flexural strength of steel slag incorporated concrete.

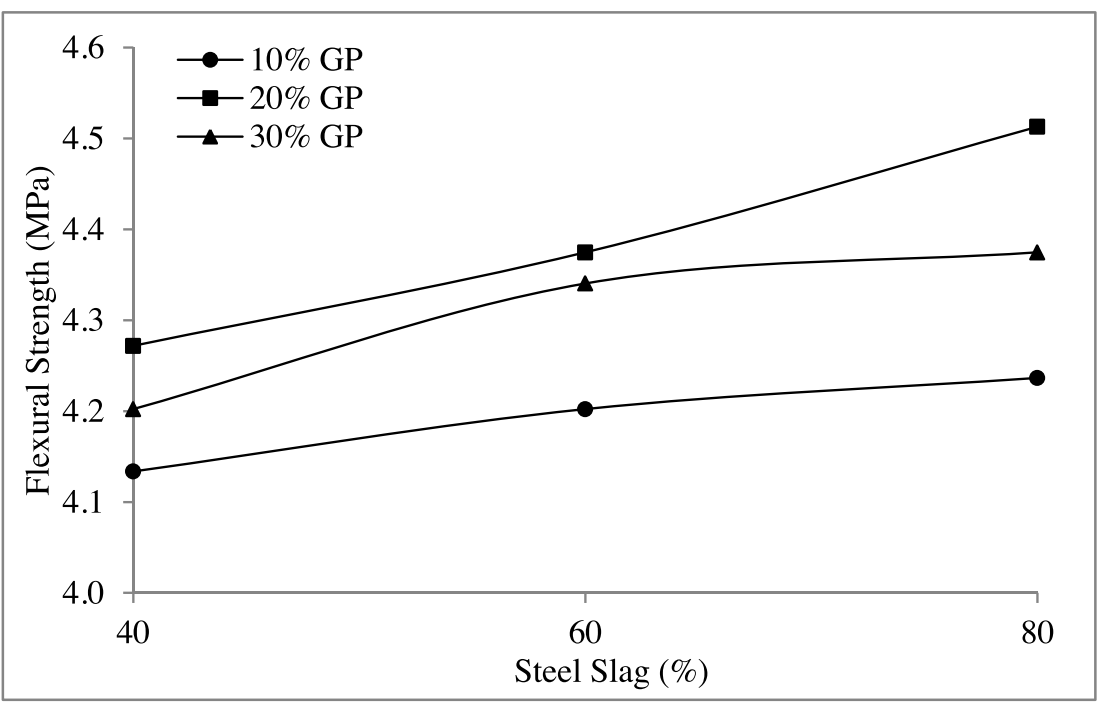

Figure 9. Effect of steel slag on flexural strength of milled glass incorporated concrete.

\section{Modulus of elasticity`}

The effect of milled glass on the modulus of elasticity is shown in Figure 10, while the influence of steel slag on the modulus of elasticity of concrete is presented in Figure 11. Like other properties, the modulus of elasticity increased for $10 \%$ and $20 \%$ milled glass content, while there was no more development reported at $30 \%$ milled glass content. Similarly, the increasing quantity of steel slag enhanced the modulus of elasticity of concrete. The highest modulus of elasticity is reported when $80 \%$ steel slag and $20 \%$ milled glass were added in the mixture. This increase in the modulus of elasticity was $16 \%$ higher than the reference concrete. This increase is due to the reduction of porosity and better pore refinement because of additional CSH production as reported by Heriyanto et al. (2018). 


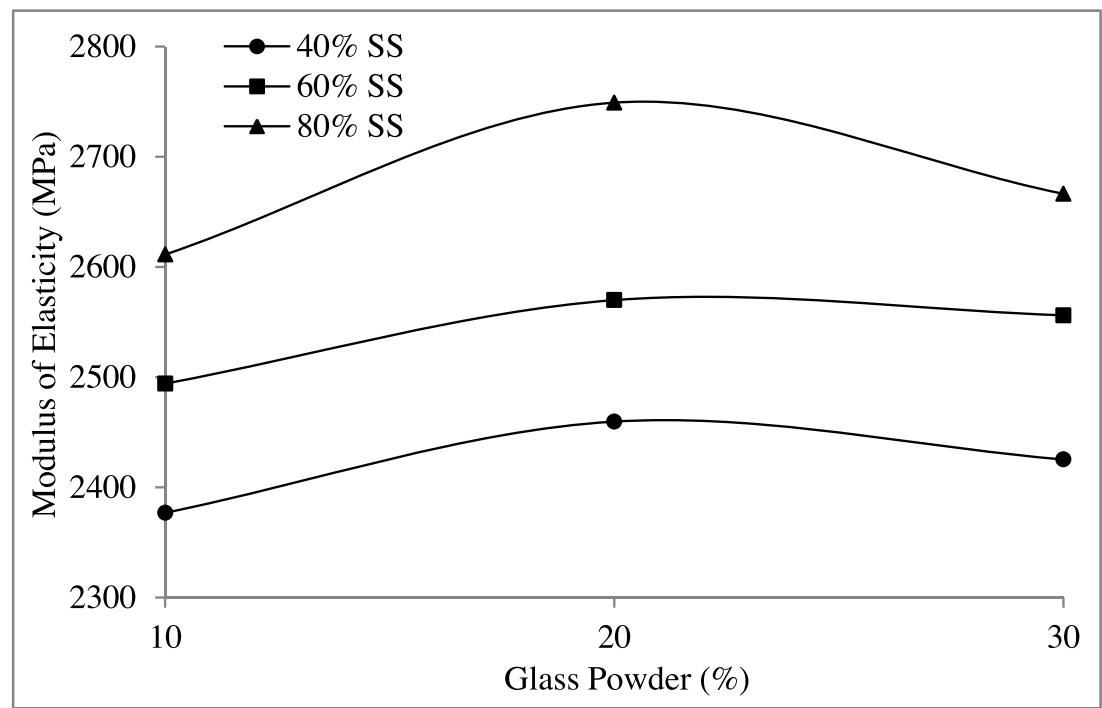

Figure 10. Effect of milled glass on modulus of elasticity of steel slag incorporated concrete.

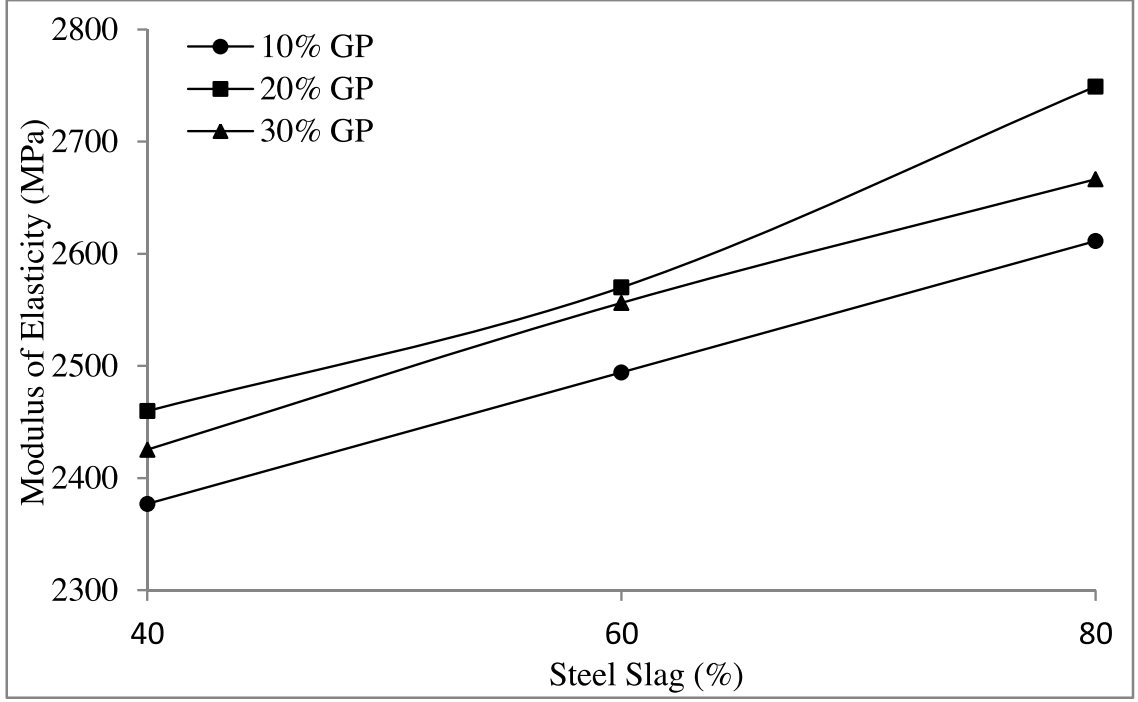

Figure 11. Effect of steel slag on modulus of elasticity of milled glass incorporated concrete.

\section{Microstructure analysis}

To study the microstructure of concrete specimens, scanning electron microscopy (SEM) was performed on test specimens after performing compressive strength test at 28 days of age. The SEM analysis for all the concrete specimens is shown in Figure 12. The results showed that milled glass enhanced the formation of secondary $\mathrm{CH}$ and $\mathrm{CSH}$. It also improves the pore structure of the concrete, which is the result of secondary CSH production due to pozzolanic reaction (Rodier and Savastano 2018). This can be seen in Fig. 12(C1), Fig. 12(C4), and Fig. 12(C7), which contains $10 \%, 20 \%$, and $30 \%$ milled glass at $40 \%$ steel slag content, respectively. Similarly, the increase in the amount of steel slag caused a reduction in the volume of voids and pores. This can be seen in Fig. 12(C4), Fig. 12(C5), and Fig. 12(C6), which contains $40 \%, 60 \%$, and $80 \%$ steel slag at $20 \%$ milled glass content, respectively. The strength parameters of concrete depend on the microstructure of concrete. The results for mechanical properties for concrete mixture C6 are 
higher than other mixtures of concrete. The mixture C6 has a more compact structure than other mixtures studied in this research as indicated by SEM analysis. Although the substitution of steel slag makes the concrete porous, but in this study, the addition of steel slag made the structure more compact. This may be due to the presence of milled glass, which resulted in a reduction in the pore formation. Also, some fine particles were also present in the steel slag, which may also have contributed to gel formation, thus resulting in a more compact structure.

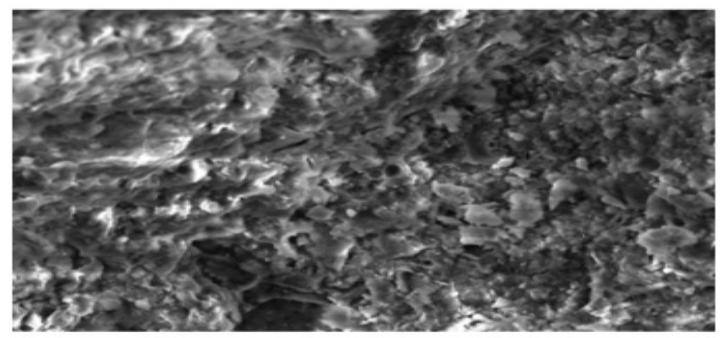

$\mathrm{C}_{\mathbf{0}}$

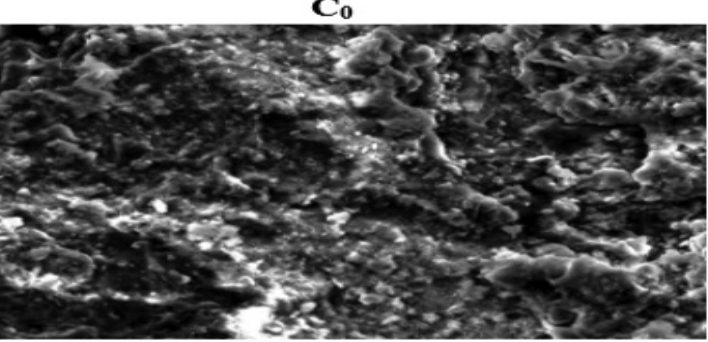

$\mathrm{C}_{2}$

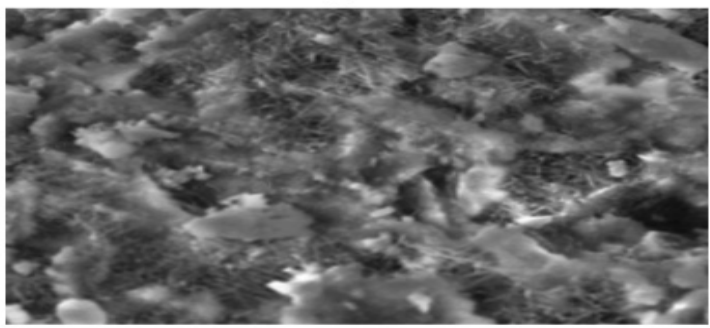

$\mathrm{C}_{4}$

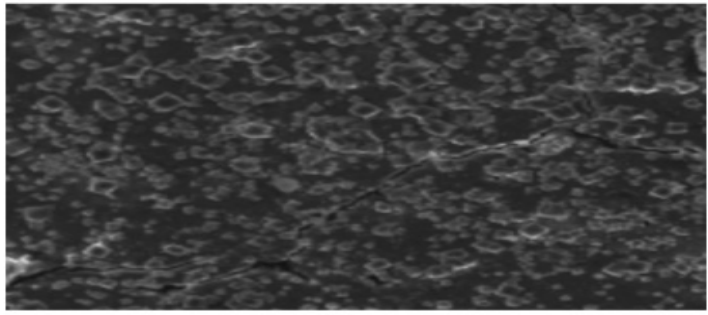

$\mathbf{C}_{6}$

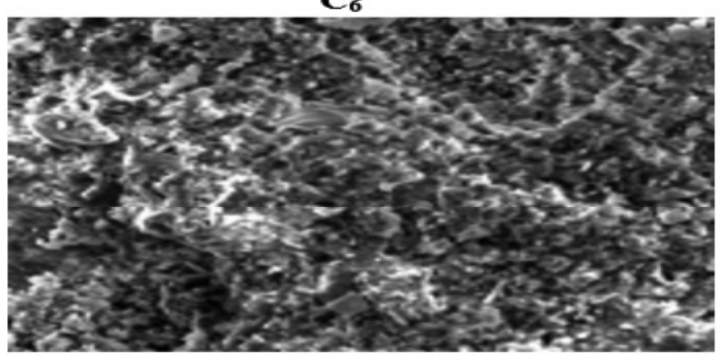

C8

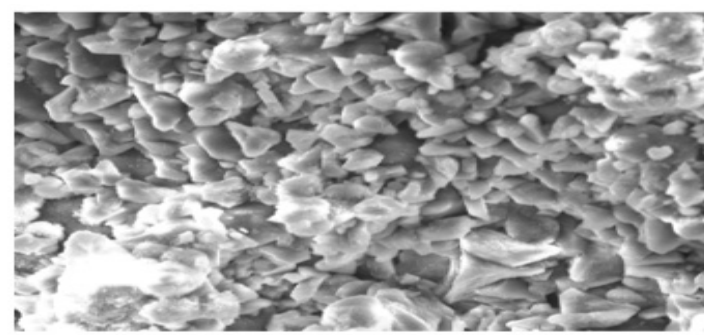

C1

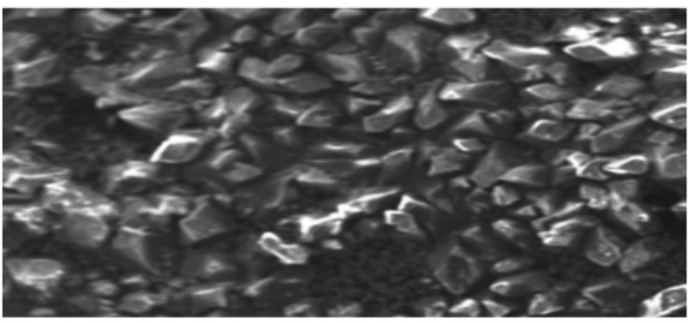

$\mathrm{C}_{3}$

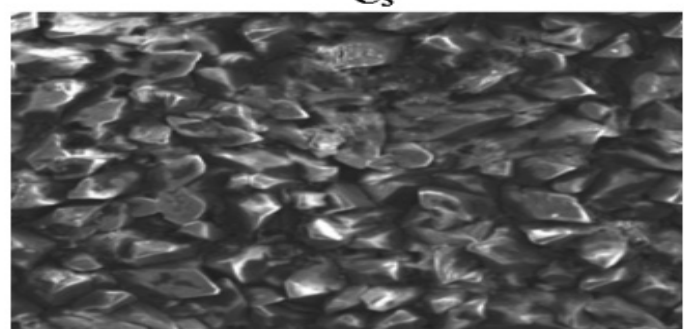

$\mathrm{C}_{5}$

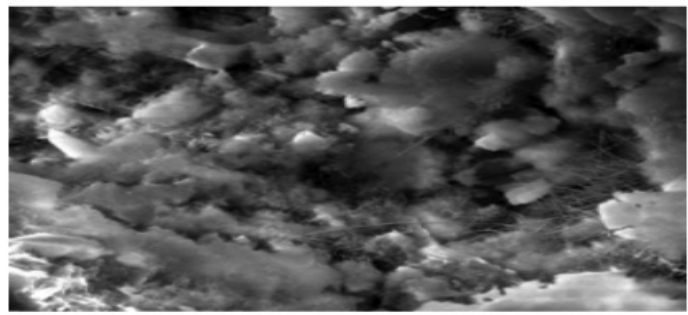

$\mathrm{C}_{7}$

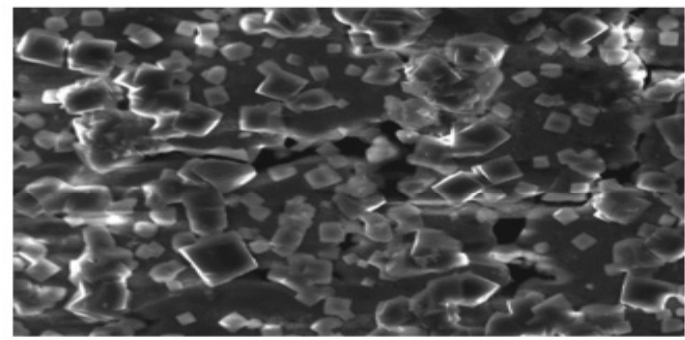

C9

Figure 12. SEM for concrete specimens after 28 days of hydration at $20 \mu \mathrm{m}$. 


\section{CONCLUSIONS AND RECOMMENDATIONS}

It is possible to develop a workable concrete and improve mechanical properties at a high content of steel slag. Thus, it is useful to use steel slag in combination with milled glass to achieve high workable concrete with good mechanical properties. The workability is influenced by the elevated amount of steel slag in the presence of $20 \%$ milled glass or above.

The maximum dosage for milled glass content in the mixture is $20 \%$. However, when steel slag was added, even higher flexural strength, splitting tensile strength, modulus of elasticity, and compressive strength were obtained at the higher quantity of milled glass. This increase could be the reason for more compact structure when these materials are added to concrete as concluded in the microstructure analysis. This also encourages the study of durability of steel slag and milled glass added concrete. Thus, it may be inferred that steel slag and milled glass can be used in the concrete taking the assistance of good workability and high mechanical properties.

Researchers are recommended to carry out further study on the durability of steel slag and milled glass added to concrete. The bond strength of concrete with rebar shall also be investigated. The concrete industry is recommended to use milled glass in combination with steel slag in concrete.

\section{REFERENCES}

Abukersh, S.A. \& Fairfield, C.A. 2011. Recycled aggregate concrete produced with red granite dust as a partial cement replacement. Construction and Building Materials, 25: 4088-94.

Afshinnia, K. \& Rangaraju, P.R. 2016. Impact of combined use of glass powder and crushed aggregate on selected properties of Portland cement concrete. Construction and Building Materials, 117: 263-72.

Ali, E.E. \& Al-Tersawy, S.H. 2012. Recycled glass as partial replacement for fine aggregate in self-compacting concrete. Construction and Building Materials, 35: 785-91.

Ali, S., Rahman, Z. \& Khan, M.K. 2017. Influence of glass powder and steel slag on properties of concrete: A reveiw. Civil Engineering Journal-Stavebni Obzor, 4: 386-93.

Aliabdo, A. A., Elmoaty, A.M.A, \& Aboshama, Y. 2016. Utilization of waste glass powder in the production of cement and concrete. Construction and Buidling Materials, 124: 866-877.

ASTM C 138. 2003. Standard Test Method for Density (Unit Weight), Yield, and Air Content (Gravimetric) of Concrete.

ASTM C 143/C 143 M. 2003. Standard Test Method for Slump of Hydraulic-Cement Concrete.

ASTM C 192/C 192M-02. 2003. Standard Practice for Making and Curing Concrete Test Specimens in the Laboratory.

ASTM C 39. 2016. Standard Test Method for Compressive Strength of Cylindrical Concrete Specimens. ASTM International.

ASTM C 469-94. 2003. Standard Test Method for Static Modulus of Elasticity and Poisson's Ratio of Concrete in Compression.

ASTM C 496-04. 2004. Standard Test Method for Splitting Tensile Strength of Cylindrical Concrete Specimens.

ASTM C 78-02. 2002. Standard Test Method for Flexural Strength of Concrete (Using Simple Beam with Third-Point Loading).

Biskri, Y., Achoura, D., Chelghoum, N. \& Mouret, M. 2017. Mechanical and durability characteristics of High Performance Concrete. Construction and Building Materials, 150: 167-78.

Castro, S.D., \& Brito, J.D. 2013. Evaluation of the durability of concrete made with crushed glass aggregates. Journal of Cleaner Production, 41: 7-4.

Crossin, E. 2015. The greenhouse gas implications of using ground granulated blast furnace slag as a cement substitute. Journal of Cleaner Production, 95: 101-108.

Deschamps, J., Simon, B. \& Hamou, A.T. 2018. Is open-loop recycling the lowest preference in a circular economy? Answering through LCA of glass powder in concrete. Journal of Cleaner Production, 185: 14-22.

González-Ortega, M.A., Seguraa, I., Cavalaroa, S.H.P., Toralles-Carbonarib, B., Aguadoa, A. \& Andrelloc, A.C. 2014. Radiological protection and mechanical properties of concretes with EAF steel slags. Construction and Building Materials 51: $432-38$.

Hou, X.D., Xu, D.L., Xue, B. \& Li, HS. 2012. Study on volume stability problems of cement caused by steel slag. Journal of 
Building Materials, 5: 589-95.

Huang, X., Z., Liu, E.Y., Hu, W. \& Ni, W. 2016. On the use of blast furnace slag and steel slag in the preparation of green artificial reef concrete. Construction and Building Materials, 112: 241-46.

Imbabi, M.S., Carrigan, C. \& Mckenna, S. 2012. Trends and development in green cement and concrete technology. International Journal of Sustainable Built Environment, 01: 194-216.

Iqbal, S., Ali, A., Holschemacher, K., Bier, T.A. \& Ribakov, Y. 2017. Effect of fly ash on properties of self-compacting high strength lightweight cooncrete. Periodica Polytechnica Civil Engineering, 61: 81-87.

Khan, M.S.H., Castel, A., Foster, S.J. \& Smith, M. 2016. Utilisation of steel furnace slag coarse aggregate in low calcium fly ash geopolymer concrete. Cement and Concrete Research, 89: 220-229.

Lu, J., Duan, Z. \& Poon, C.S. 2017. Fresh properties of cement pastes or mortars incorporating waste glass. Construction and Building Materials, 131: 793-99.

Mengxiao, S., Qiang, W. \& Zhikai, Z. 2015. Comparison of the properties between high-volume fly ash concrete and high-volume steel slag concrete under temperature matching curing condition. Construction and Building Materials, 98: 649-655.

Motz, H. \& Geiseler, J. 2001. Products of steel slags, an opportunity to save natural resources. Waste Management, 21: 285-93.

Netinger, I., Varevac, D., Bjegovic, D. \& Moric, D. 2013. Effect of high temperature on properties of steel slag aggregate concrete. Fire Safety Journal, 59: 1-7.

Parghi, A., \& Alam, M.S. 2016. Physical and chemical properties of cementitious composites contaning recycled glass powder (RGP) and styrene butadience rubber (SBR). Construction and Building Materials, 106: 34-43.

Pahlevani, F. \& Sahajwalla, V. 2018. From waste glass to building materials - an innovative sustainable solution for waste glass. Journal of Cleaner Production, 191: 192-206.

Qasrawi, H., Shalabi, F. \& Asi, I. 2009. Use of low CaO unprocessed steel slag in concrete as fine aggregate." Construction and Building Materials, 23: 1118-1125.

Raju, S., \& Kumar, P.R. 2014. Effect of Using Glass Powder in Concrete. International Conference On Innovations \& Advances In Science, Engineering And. Kerala, India. 421-27.

Rashad, A.M. 2014. Recycled waste glass as fine aggregate replacement in cementitious materials based on Portland cement. Construction and Building Materials, 72: 340-57.

Rehman, S., Iqbal, S. \& Ali. A. 2018. Combined influence of glass powder and granular steel slag on fresh and mechanical properties of self-compacting concrete. Construction and Building Materials, 178: 153-60.

Rodier, L., \& Holmer, S. 2018. Use of glass powder residue for the elaboration of eco-efficient cementitious materials. Journal of Cleaner Production, 184: 333-341.

Roslan, N.H., Ismail, M., Abdul-Majid, Z. \& Muhammad, B. 2016. Performance of steel slag and steel sludge in concrete. Construction and Building Materials, 104: 16-24.

San-Jose, J.T., Vegas, I., Arribas, I. \& Marcos, I. 2014. The performance of steel-making slag concrete in the hardened state. Materials and Design, 60: 612-619.

Schwarz, N., DuBois, M. \& Neithalath, N. 2007. Electrical conductivity based characterization of plain and coarse powder modified cement paste. Cement and Concrete Research, 29: 656-666.

Silva, R.V., Brito, J.D. \& Dhir, R.K. 2014. Properties and composition of recycled aggregates from construction and demolition waste for concrete production. Construction and Building Materials, 65: 201-217.

Srivastava, V., Kumar, R., Agarwal, V.C. \& Mehta, P.K. 2015. Effect of Silica Fume on Workability and Compressive Strength of OPC Concrete. Journal of Environmental Nanotechnology, 3: 32-35.

Tho-In, T., Sata, V., Boonserm, K. \& Chindaprasirt, P. 2018. Compressive strength and microstructure analysis of geopolymer paste using waste glass powder and fly ash. Journal of Cleaner Production, 172: 2892-2898.

Yu, X., Tao, Z., Song,T.Y. \& Pan. Z. 2016. Performance of concrete made with steel slag and waste glass.Construction and Building Materials, 114: 737-46.

Zelic, J. 2005. Properties of concrete pavement prepared with ferrochromium slag as concrete aggregate. Cement and Concrete Research, 35: 2340-2349. 